\title{
Avaliação do efeito da sertralina sobre os tecidos periodontais de ratos Wistar com periodontite induzida
}

Evaluation of the effect of sertraline on periodontal tissues in Wistar Rats with induced periodontitis

Evaluación del efecto de sertralina sobre los tejidos periodontales en ratas Wistar con periodontitis inducida

Recebido: 29/04/2021 | Revisado: 05/05/2021 | Aceito: 08/05/2021 | Publicado: 10/06/2021

\author{
Bruna Rafaela Correia \\ ORCID: https://orcid.org/0000-0001-9453-4852 \\ Universidade Estadual do Oeste do Paraná, Brasil \\ E-mail:bru_na_rafac@hotmail.com \\ Carlos. Augusto Nassar \\ ORCID: https://orcid.org/0000-0002-8647-413X \\ Universidade Estadual do Oeste do Paraná, Brasil \\ E-mail:carlos.nassar@unioeste.br \\ Franciele Fernanda Adada \\ ORCID: https://orcid.org/0000-0002-6819-2833 \\ Universidade Estadual do Oeste do Paraná, Brasil \\ E-mail:franadada19@gmail.com \\ Patricia Oehlmeyer Nassar \\ ORCID: https://orcid.org/0000-0003-3791-0334 \\ Universidade Estadual do Oeste do Paraná, Brasil \\ E-mail:ponassar@yahoo.com \\ Sabrina Grassiolli \\ ORCID: https://orcid.org/0000-0001-5647-7877 \\ Universidade Estadual do Oeste do Paraná, Brasil \\ E-mail:sgrassiolli@gmail.com \\ Thais Carolina Schnaufer \\ ORCID: https://orcid.org/0000-0003-1589-8856 \\ Universidade Estadual do Oeste do Paraná, Brasil \\ E-mail:thaisschnaufer@hotmail.com
}

\begin{abstract}
Resumo
A Saúde bucal está associada a doenças sistêmicas devido presença de microorganismos e, depressão é uma das patologias sistêmicas e um dos medicamentos para tratamento, é sertralina. Este estudo tem por objetivo avaliar os efeitos da sertralina em tecidos periodontais com ratos induzidos a periodontite por ligadura. Foram utilizados 40 ratos machos adultos, divididos em 4 grupos, grupo controle (GC), grupo com doença periodontal, (GDP), grupo sertralina (GS) e grupo doença periodontal e sertralina (GDPS). Os grupos com doença periodontal receberam uma ligadura ao redor dos primeiros molares pelo período de 30 dias, indução da doença ocorreu com os animais anestesiados e auxílio de pinça modificada, sonda exploradora, adicionando fio de algodão número 40 ao redor do primeiro molar inferior de ambos lados. Nos animais grupos GS e GDPS foram administradas doses de $5 \mathrm{mg} / \mathrm{kg}$, os animais grupos GDP e GC receberam $1 \mathrm{~mL} / \mathrm{Kg}$ de peso de solução fisiológica, avaliando consumo durante este período. Após período, os animais foram eutanasiados, com as hemi-mandíbulas retiradas e submetidas à análise histológica, morfológica e radiográfica. Os resultados, analisados pelo programa GraphPad Programa, apresentaram que animais GDP e GDPS não demonstraram diferença estatisticamente significante entre si $(p>0,05)$, entretanto foram significativamente diferente dos outros grupos que não houve indução da doença periodontal ( $\mathrm{p}<0,05)$. Assim, a sertralina na dose de $5 \mathrm{mg} / \mathrm{kg}$ não promoveu efeito sobre os tecidos periodontais de ratos com doença periodontal induzida por ligadura.
\end{abstract}

Palavras-chave: Doença periodontal; Sertralina; Hemi-mandíbulas.

\begin{abstract}
Oral health is associated with systemic diseases due to the presence of microorganisms and, depression is one of the systemic pathologies and one of the drugs for treatment is sertraline. This study aims to evaluate the effects of sertraline in periodontal tissues with rats induced to ligation periodontitis. 40 adult male rats were used, divided into 4 groups, control group (CG), group with periodontal disease, (GDP), sertraline group (GS) and periodontal disease and sertraline group (GDPS). The groups with periodontal disease received a bandage around the first molars for a period of 30 days,
\end{abstract}


disease induction occurred with the anesthetized animals and the aid of a modified clamp, explorer probe, adding cotton thread number 40 around the lower first molar of both sides. In the animals groups GS and GDPS, doses of $5 \mathrm{mg} / \mathrm{kg}$ were administered, the animals groups GDP and GC received $1 \mathrm{~mL} / \mathrm{kg}$ of saline solution, assessing consumption during this period. After a period, the animals were euthanized, with the hemi-mandibles removed and submitted to histological, morphological and radiographic analysis. The results, analyzed by the GraphPad Program, showed that GDP and GDPS animals did not show a statistically significant difference between them $(\mathrm{p}>0.05)$, however they were significantly different from the other groups that did not induce periodontal disease $(\mathrm{p}<0.05)$. Thus, sertraline at a dose of $5 \mathrm{mg} / \mathrm{kg}$ did not promote an effect on the periodontal tissues of rats with ligature-induced periodontal disease.

Keywords: Periodontal disease; Sertraline; Hemi-jaws.

\section{Resumen}

La salud bucal se asocia a enfermedades sistémicas por la presencia de microorganismos y la depresión es una de las patologías sistémicas y uno de los fármacos de tratamiento es la sertralina. Este estudio tiene como objetivo evaluar los efectos de la sertralina en tejidos periodontales con ratas inducidas a ligadura de periodontitis. Se utilizaron 40 ratas macho adultas, divididas en 4 grupos, grupo control (GC), grupo con enfermedad periodontal, (GDP), grupo sertralina (GS) y grupo enfermedad periodontal y grupo sertralina (GDPS). Los grupos con enfermedad periodontal recibieron un vendaje alrededor de los primeros molares por un período de 30 días, la inducción de la enfermedad ocurrió con los animales anestesiados y la ayuda de fórceps modificados, sonda exploradora, agregando hilo de algodón número 40 alrededor del primer molar inferior de ambos lados. . En los grupos de animales GS y GDPS se administraron dosis de $5 \mathrm{mg} / \mathrm{kg}$, los grupos de animales GDP y GC recibieron $1 \mathrm{~mL} / \mathrm{kg}$ de solución salina, evaluando el consumo durante este período. Después de un período, los animales fueron sacrificados, con la extracción de las hemi-mandíbulas y sometidos a análisis histológico, morfológico y radiográfico. Los resultados, analizados por el Programa GraphPad, mostraron que los animales GDP y GDPS no mostraron una diferencia estadísticamente significativa entre ellos ( $p>$ 0.05), sin embargo fueron significativamente diferentes de los otros grupos que no indujeron enfermedad periodontal ( $\mathrm{p}<0.05)$. Por tanto, la sertralina a una dosis de $5 \mathrm{mg} / \mathrm{kg}$ no promovió un efecto sobre los tejidos periodontales de ratas con enfermedad periodontal inducida por ligadura.

Palabras clave: Enfermedad periodontal; Sertralina; Hemi-mandíbulas.

\section{Introdução}

A doença periodontal é considerada uma das mais comuns enfermidades dentárias local e inflamatória causada por infecção bacteriana que pode estar associada à placa dental (Antonini et al., 2013). A inflamação periodontal leva a um aprofundamento excessivo do sulco gengival através da migração apical do epitélio juncional, destruindo o ligamento periodontal, do cemento e do osso alveolar (Abreu et al., 2010; Rettori. et al.). Clinicamente a periodontite é caracterizada pelo prejuízo de inserção, na formação de bolsa e mudança na espessura e estatura do osso alveolar subjacente (Newman, et al., 2011).

Esta doença inicia com o desenvolvimento da gengivite, a qual pode ou não evoluir para periodontite (Alves et al., 2007) e assim, pode ocasionar, perda dentária, devido a presença de bactérias Gram-negativas (BGN) anaeróbicas na cavidade bucal, o qual promove a perda da inserção dental (Albuquerque; Pinto; Moreira, 2014; Antonini et al., 2013; Steffens; Marcantonio, 2018).

As bactérias orais decorrentes do processo de doença periodontal liberam diversas citocinas pró-inflamatórias locais, as quais também são responsáveis pela inflamação sistêmica (Garlet et al., 2012; LINS et al., 2007; schenkein; Loos, 2013; Pandini, 2019). A doença periodontal caracteriza-se pelo aumento dos níveis circulantes de mediadores pró-inflamatórios sistêmicos como a proteína C reativa (PCR), interleucina 1 (IL-1), IL-6, IL-12, IL-18 e IL-21 e na diminuição dos níveis de mediadores antiinflamatórios como a IL-4 (Leishman; Seymour; Ford, 2013; Mootha et al., 2016; Schenkein; Loos, 2013).

Em consequência, a inflamação atinge as estruturas de fixação dos dentes (tecidos gengivais, ligamento periodontal e osso alveolar), a reabsorção do osso alveolar, a qual é responsável pela perda dental, expressa a perturbação da homeostase entre a resposta imune do hospedeiro e o agente causador (Garlet et al., 2012; Hajishengallis, 2015; Mootha et al., 2016). 
Atualmente, já está bem estabelecido na literatura que a doença periodontal pode ser um fator de risco para o desenvolvimento de distúrbios sistêmicos (Nagpal; Yamashiro; Izumi, 2015), por exemplo, a depressão (Genco et al., 1999). Doença que mais aumenta nos dias atuais, indiferente da idade das pessoas, segundo a Organização Mundial da Saúde (OMS) (ONU, 2017). E, no Brasil, a depressão é a terceira doença que mais causa autorização de auxílio doença pelo Instituto Nacional do Seguro Social (INSS) (Jardim, 2011), ademais, promove milhares de vítimas de suicídio no mundo (OMS, 2018).

Esta patologia vem sendo estudada desde a antiguidade, pois não é um fenômeno dos dias atuais (Assumpção; Oliveira; Souza, 2018). A depressão possui características e sintomas específicos (Santiago; Holanda 2013), a patologia apresenta momentos recorrentes e distintos episódios depressivos, sem a remissão dos sintomas, enquanto que, a distimia (depressão menor), aponta o curso de mais brando desta patologia (Orsini; Ribeiro, 2012).

A depressão apresenta seguimentos ciclotímicos, melancolia e transtorno bipolar (TBP) (rodrigues; Brisky; Soczek, 2017), bem como, tempos com depressão e mania, e outras vezes, com ciclos de depressão e hipomania (Bosaipo; Borges; Juruena, 2017).

Assim, fármacos que atuam alterando o comportamento, cognição e o humor no Sistema Nervoso Central (SNC), recebem o nome de psicotrópicos (Prado; Francisco; Barros, 2017), dentre estes medicamentos estão os fármacos inibidores seletivos de receptação de serotonina (ISRS), que promovem maior quantidade de serotonina e possibilitam sua manutenção na fenda sináptica (Paula, 2007; Feijó; Bertoluci; Reis, 2010).

Nesta classe farmacológica, encontra-se a sertralina, desenvolvida em 1991 por Kenneth Koe e colaboradores (Landau; Achilladelis; Sriabine, 1999), com a denominação de Zoloft @ (Grobler; Matthews; Molenberghs, 2014) e tempo de atuação de 26 horas (Moura, 2014).

Este fármaco ativo, ao sofrer a ação enzimática do fígado, transforma-se na configuração inativa de desmetilsertralina e desta forma, passa a ser excretada pelas fezes e na urina (Landau; Achilladelis; Sriabine, 1999; Moura, 2014; Moreno; Moreno; Soares, 1999; Schatzberg; Nemeroff, 2009). Seus efeitos colaterais são a insônia, diminuição da libido, tontura, dor de cabeça, diarreia, náusea, boca seca, fadiga, além da síndrome de abstinência ao ser retirada abruptamente (ANVISA, 2014).

Estudo de Abu Nada e colaboradores (2018) evidenciou que, a sertralina tem um efeito negativo na cicatrização óssea e na ósseaintegração do implante de titânio na tíbia de ratos, podendo representar fator de risco potencial para implantes dentários e cirurgias ortopédicas, interferindo com a cicatrização óssea, provavelmente diminuindo o número de osteoblastos e aumentando o número de osteoclastos.

O mecanismo de ação da sertralina na cicatrização óssea pode ser atribuído ao seu efeito sobre a função imune, na angiogênese, nas vias de sinalização adrenérgica e na via nicotínica. Entretanto, os efeitos da sertralina sobre os tecidos periodontais de sustentação, ainda permanece desconhecido, pois não há relatos na literatura de sua ação sobre os tecidos periodontais, tanto em humanos como em animais.

E, como a depressão é uma doença sistêmica (Sotelo; Nemeroff, 2017), a doença periodontal ou periodontite também pode estar associada a essa classe (Page, 1998). Como mencionado anteriormente a doença periodontal, no entanto, é causada por bactérias presentes na cavidade bucal e assim, promovem o aumento das células inflamatórias no organismo (Albuquerque; Pinto; Moreira, 2014; Steffens; Marcantonio, 2018).

O objetivo do estudo foi avaliar os efeitos da sertralina em tecidos periodontais com ratos induzidos a periodontite por ligadura. 


\section{Metodologia}

Para este estudo, foram obtidos 40 animais ratos Wistar do biotério central da UNIOESTE com 21 dias de vida, sendo os mesmos separados ao acaso em caixas e subdivididos em 4 grupos totalizando 40 animais, com os grupos assim formados (figura 1):

1- Grupo Controle (GC): sem doença e sem tratamento;

2- Grupo Sertralina (GS): ratos que receberam a administração de sertralina via oral;

3- Grupo Doença Periodontal (GDP): na qual foi induzida a doença periodontal por ligadura;

4- Grupo Doença Periodontal e Sertralina (GDPS): ratos foram submetidos à administração de sertralina via oral e indução da doença periodontal por ligadura.

Figura 1: Grupos de animais de pesquisa.

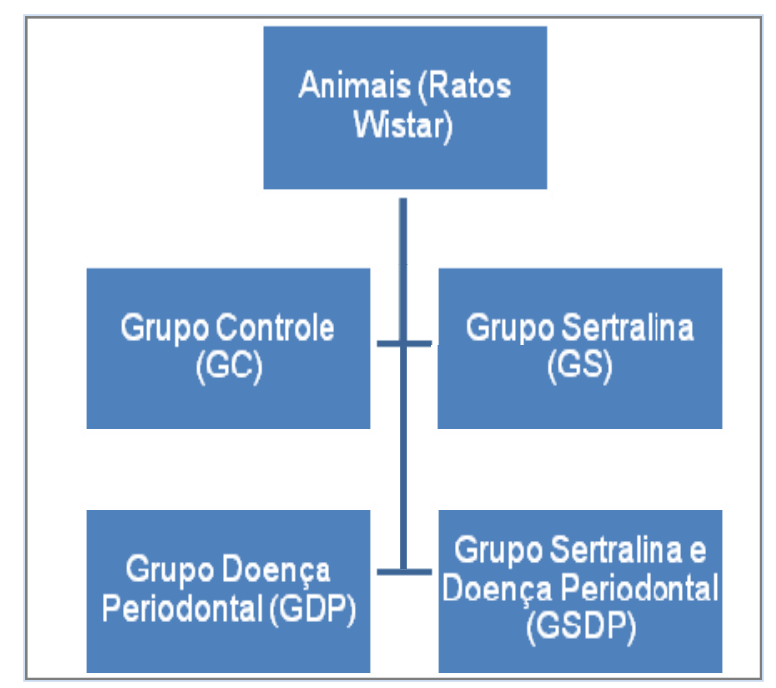

Fonte: Autores (2019).

O projeto foi aprovado previamente pelo Comitê de Ética no Uso de Animais (CEUA) da UNIOESTE, estando de acordo com os Princípios Éticos na Experimentação Animal, adotados pelo Conselho Nacional de Controle de Experimentação Animal (CONCEA). Trata-se de uma pesquisa com abordagem quantitativa, classificada quanto a sua finalidade como básica, quanto ao objetivo como descritiva e de caráter experimental (Gil, 2009).

\subsection{Consumo alimentar}

As análises do peso corporal dos mesmos, foi realizada a cada dois dias na semana, onde os valores do peso final (PF) foram diminuídos em relação ao peso inicial (PI) e obtido os ganhos de peso (Nery et al., 2011). No entanto, o consumo ocorria 3x na semana, assim estes resultados foram subtraídos em relação a sobra de alimentos da data anterior (Nery et al., 2011). Para a análise da eficiência alimentar, o valor obtido do consumo de alimentos foi dividido pelo número de ratos que estavam na caixa e posteriormente, este resultado foi novamente dividido pelo peso do animal separadamente, o qual obteve-se o cálculo amostral de $\mathrm{g} / 100 \mathrm{~g}$ de kg peso corporal dos mesmos.

\subsection{Indução da doença periodontal (DP)}

Aos 30 dias de vida, os grupos com periodontite receberam uma ligadura ao redor dos $1^{\circ}$ molares inferiores, o qual atuou como agente irritante gengival mecânico, assim elevando o número de bactérias e possibilitando a ação imunológica no 
periodonto (Peralta, 2008), pelo período de 30 dias e desta forma, induzindo o desenvolvimento da doença periodontal experimentalmente (Cavagni et al., 2005).

Conforme protocolo estabelecido por Nassar e colaboradores (2009), a indução da doença foi realizada com os animais anestesiados com cloridrato de quetamina (50mg/Kg de peso corporal) e cloridrato de xilazina ( $15 \mathrm{mg} / \mathrm{Kg}$ de peso corporal). Estes animais posteriormente foram posicionados em mesa operatória apropriada, a qual permitiu a manutenção da abertura bucal dos ratos e assim, facilitando o acesso aos dentes da região posterior da mandíbula.

Com auxílio de uma pinça modificada e de uma sonda exploradora, foi colocado um fio de algodão número 40 ao redor do $1^{\circ}$ molar inferior de ambos os lados, sendo que os animais tiveram restrição alimentar 8 horas antes do procedimento da indução da doença, bem como, após a cirurgia receberam 1 gota de dipirona sódica para a dor e febre.

\subsection{Administração da sertralina}

Após a indução da doença periodontal, os animais dos grupos sertralina (GS e GDPS), receberam doses diárias (5mg/kg de peso corporal, via oral pelo método de gavagem) em dias alternados até completar os 60 dias de vida, o qual era diluído em solução fisiológica $0,9 \%$. Enquanto que, os animais dos outros grupos (GC e GDP) receberam $1 \mathrm{~mL} / \mathrm{Kg}$ de peso de solução fisiológica $0,9 \%$ para induzir o mesmo estresse entre ambos os grupos, esta pesquisa foi adaptada, de acordo com o estudo desenvolvido por Atli e colaboradores (2017) (Figura 2).

Figura 2: Delineamento da indução da doença periodontal e administração da sertralina.

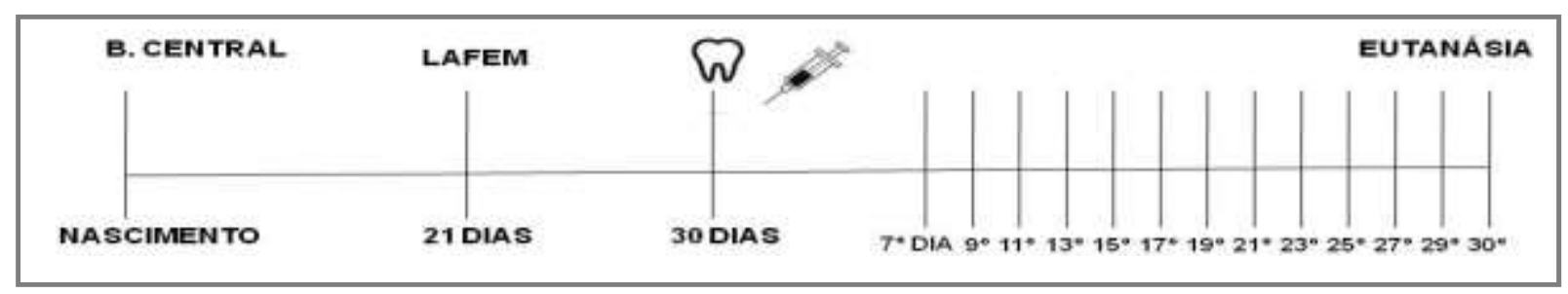

Fonte: Autores (2019).

\subsection{Eutanásia dos animais}

No último dia de experimento $\left(30^{\circ}\right)$, todos os animais foram pesados e, em seguida, sedados na câmara de $\mathrm{CO}^{2}$ e depois foi utilizada a guilhotina. Sendo realizada a coleta das hemi-mandíbulas do lado direito e esquerdo.

\subsection{Análise do peso dos rins e fígado}

Após as eutanásias, os rins e o fígado dos animais foram separados e seus pesos foram mensurados através do uso de uma balança analítica, para avaliar o efeito da sertralina sobre o peso destes órgãos.

\subsection{Processamento histológico}

As hemi-mandíbulas esquerdas foram coletadas, dissecadas e fixadas em solução de Metacarn, por 48 horas. Após este período, foram adicionadas em álcool 70\%, até iniciar o processamento histológico. Logo, foram lavadas em água corrente por 3 dias e assim, imersas em solução de ácido tricloroacético (TCA) 5\% por 3 semanas, sendo avaliadas 3x na semana até atingirem o grau esperado de descalcificação.

Após este período, as mesmas foram novamente lavadas em água corrente por 18 horas e posteriormente realizado o processamento histológico, onde as peças foram imersas em graduações de alcoóis (para desidratação) e xilol (para diafanização). 
A partir deste, seguiram a inclusão das peças e obtenção de blocos de parafina (Parafina Purificada, cód. 1228, lote 1008459, Vetec Química Fina, Rio de Janeiro, Brasil). Os mesmos foram cortados em micrótomo manual e obtidos cortes de 7 $\mu \mathrm{m}$, que foram adicionados em lâminas histológicas, juntamente com solução diluída de albumina e corados pela técnica histoquímica de Hematoxilina e Eosina (H\&E) e posteriormente, com auxílio do Entellan, as lamínulas foram coladas em cima destes tecidos, para que assim, serem observadas em microscopia (Junqueira; Carneiro, 2008).

\subsection{Observações microscópicas}

As análises microscópicas foram realizadas por 3 examinadores através da avaliação dos cortes histológicos corados. As lâminas foram analisadas com auxílio de um microscópio de luz (Leica Microsystems, Switzerland) e fotomicrografadas em microscópio Olympus® DP71 (USA), comumente transmitida para observações morfológicas do tecido gengival, processo alveolar e contagem de osteoblastos, osteócitos e osteoclastos das hemi-mandíbulas dos animais.

\subsection{Morfometria do osso e da gengiva}

Foram realizadas as quantificações de osteoblastos, osteócitos e oesteoclastos presentes em 5 campos consecutivos da crista óssea alveolar vestibular partindo do ponto mais alto da crista. Para a observação foi utilizado o aumento de 1000 vezes em imersão no microscópio. Sendo feitas duas observações por campo, e então, feito a média dos valores para cada animal e para cada grupo.

A medida da crista óssea alveolar, bem como, altura do tecido epitelial e conjuntivo e a largura de ambos os tecidos, foram realizadas através de um microscópio acoplado a um computador, o qual permitiu capturar as imagens, através do software $L a z E z \circledR$. Sendo realizada uma medida da menor distância entre o ápice da crista óssea alveolar vestibular e a junção cementoesmalte, utilizando um programa analisador de imagens Image Tools 3.0 (University of Texas Health Science Center, San Antonio, TX, USA). Em todas as medidas foram repetidas uma vez por dia, em três dias diferentes, e então, realizadas uma média entre os valores (Mattia et al., 2017).

As medidas morfométricas foram feitas nas gengivas marginais, vestibular e lingual direita em todos os grupos, utilizando-se um programa analisador de imagens (Image Tool 3.0), acoplado a um microscópio de luz com objetiva de 10x, a intervalos de 10 cortes entre uma contagem e outra no seriamento dos cortes (cerca de $50 \mu \mathrm{m}$ ) (Mattia et al., 2017).

As mensurações foram feitas a partir de pontos morfológicos pré-determinados na gengiva marginal, como ilustrado na Figura 3. Os resultados foram expressos em $\mu \mathrm{m}$. Além destas foram verificados a área total da gengiva e do tecido conjuntivo. 
Figura 3: Imagem: Fotomicrografia com aumento de 400x através do Fotomicroscópio Olympus® e com coloração de Hematoxilina e Eosina. As medidas representam as distâncias da crista óssea alveolar, tecido epitelial e tecido conjuntivo do primeiro molar inferior dos animais. (A. Medida da crista óssea alveolar do lado esquerdo B. Medida da crista óssea alveolar do lado direito C. Medida da altura do tecido epitelial do lado direito D. Medida da largura do tecido epitelial do lado direito E. Medida da altura do tecido conjuntivo do lado direito F. Medida da largura do tecido conjuntivo do lado direito).

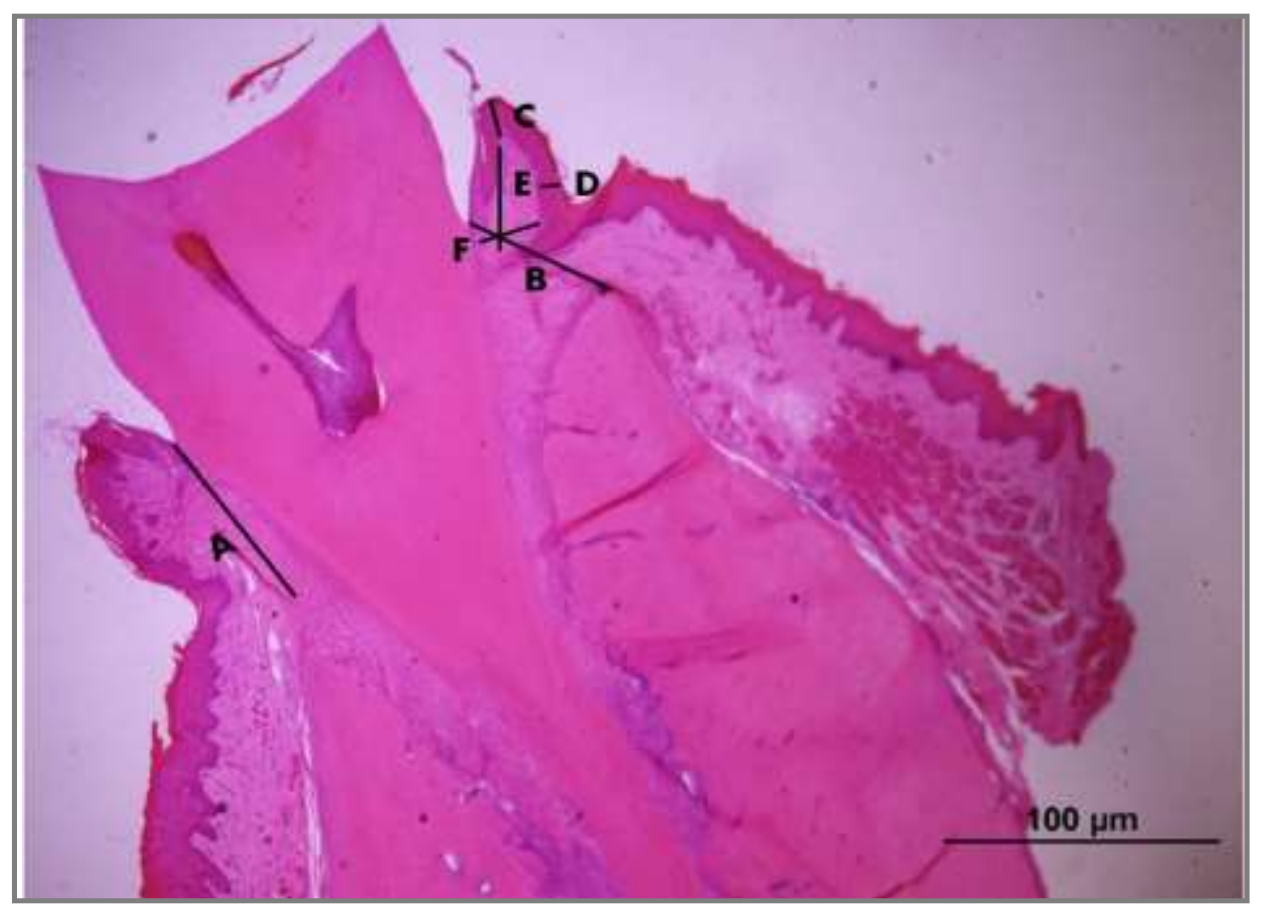

Fonte: Autores (2019).

\subsection{Análise radiográfica}

Logo após a eutanásia, as hemi-mandíbulas do lado direito de cada animal foram retiradas, fixadas em Metacarn durante 48 horas e posteriormente mantidas em álcool $70 \%$, até suas análises.

As hemi-mandíbulas foram colocadas com a face lingual sobre o sensor radiográfico digital Kodak RVG 6100 com resolução de imagem $20 \mathrm{pl} / \mathrm{mm}$, resolução teórica do sensor 27,03 pl/mm, fibra ótica 1, dimensões de superfície ativa de 22 x 30 mm e dimensões da matriz (pixels) 1200 x 1600 (1,92 milhões) e posicionados para que as cúspides vestibulares e linguais dos primeiros molares fiquem no mesmo plano vertical. Foi utilizado aparelho de raio X GE - 1000, regulado para $15 \mathrm{~mA}, 65 \mathrm{Vp}, 18$ impulsos, distância foco/filme de 50 centímetros com incidência de raio $\mathrm{X}$ perpendicular às peças. As imagens digitalizadas foram analisadas no programa Image Tools 3.0 (University of Texas Health Science Center, San Antonio, TX, USA), na qual foram realizadas medidas lineares que percorrerão a distância da junção cemento-esmalte até a crista óssea alveolar do lado mesial do primeiro molar inferior direito (figura 4), essas medidas foram repetidas uma vez por dia, em três dias diferentes, e realizado uma média entre os valores, com as medições em pixels (Nassar et al., 2009). 
Figura 4: Foto da hemi-mandíbula de ratos.

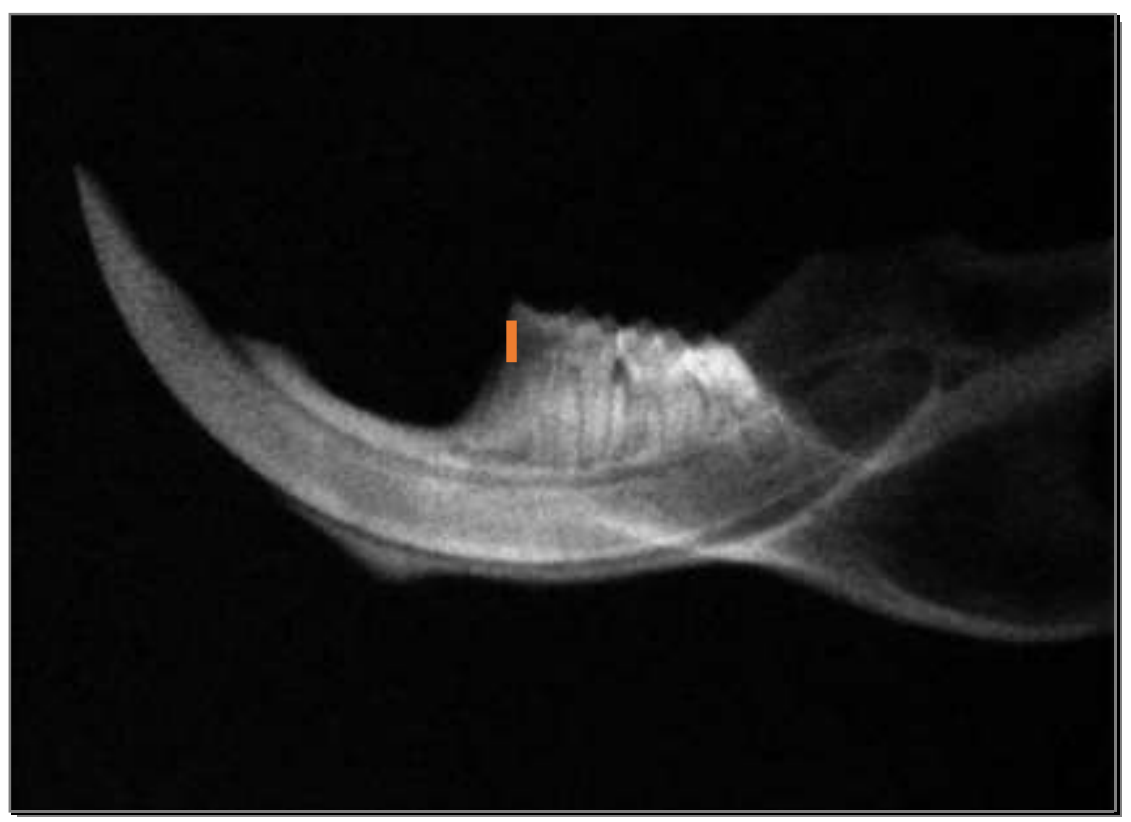

Fonte: Autores (2019).

\subsection{Análise de dados}

Os resultados foram analisados usando o programa Graph Pad Prism 8.0®. Em todas as variáveis foram testadas a distribuição normal e a variância homogênea. Quando a distribuição for considerada normal e à variância homogênea foram utilizados os testes paramétricos ANOVA - Oneway seguido pelo pós-teste de comparação múltipla de Tukey. As diferenças observadas foram consideradas significantes quando $\mathrm{p}<0,05(5 \%)$.

\section{Resultados e Discussão}

Após a chegada destes animais no biotério, seus pesos e o consumo de alimentos passaram a ser quantificados, para que assim, obtivesse os resultados do consumo alimentar, onde demonstram que não apresentaram alteração estatisticamente significativa entre os 4 grupos, conforme são descritos no Gráfico 1, seguindo o teste de ANOVA e pós teste de Tukey. 
Gráfico 1: Avaliação da eficiência alimentar dos animais.

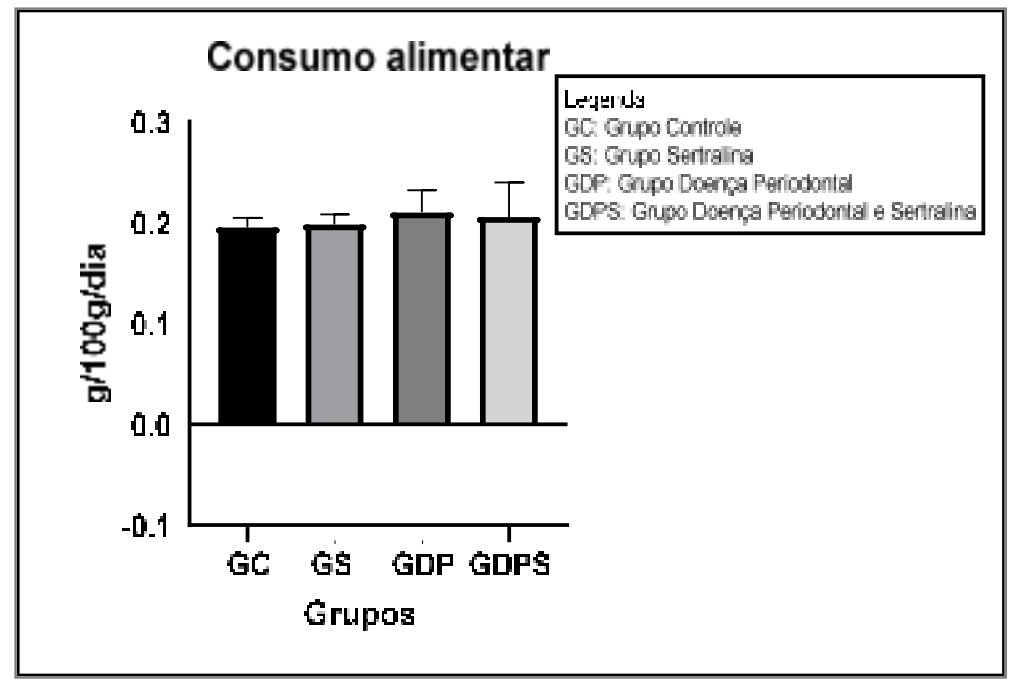

Fonte: Autores (2019).

Com a administração de sertralina nos grupos GS e GDPS, consequentemente os mesmos não apresentaram valores estatísticos significativos quando comparados aos grupos GC e GDP, em relação a eficiência alimentar (gráfico 1). Além do que, os ratos apresentam uma maior uniformidade em relação a dose administrada de medicamentos quando comparados aos seres humanos (Coltri et al., 2017; Foureaux et al., 2014; Atli et al., 2017).

Na Figura 5 apresenta-se os resultados em relação ao uso da sertralina e/ou doença periodontal nos rins, respectivamente. Os valores em peso dos rins direitos e esquerdos foram analisados em relação aos seus pesos, demonstrando que o uso da sertralina não apresentou alteração em relação ao peso dos mesmos, quando comparados os 4 grupos, uma vez que houve diferença estatística significante entre eles $(p>0,05)$ referente ao teste de ANOVA e seguido pós teste de Tukey.

Figura 5: Gráficos dos efeitos da sertralina e/ou doença periodontal nos rins.

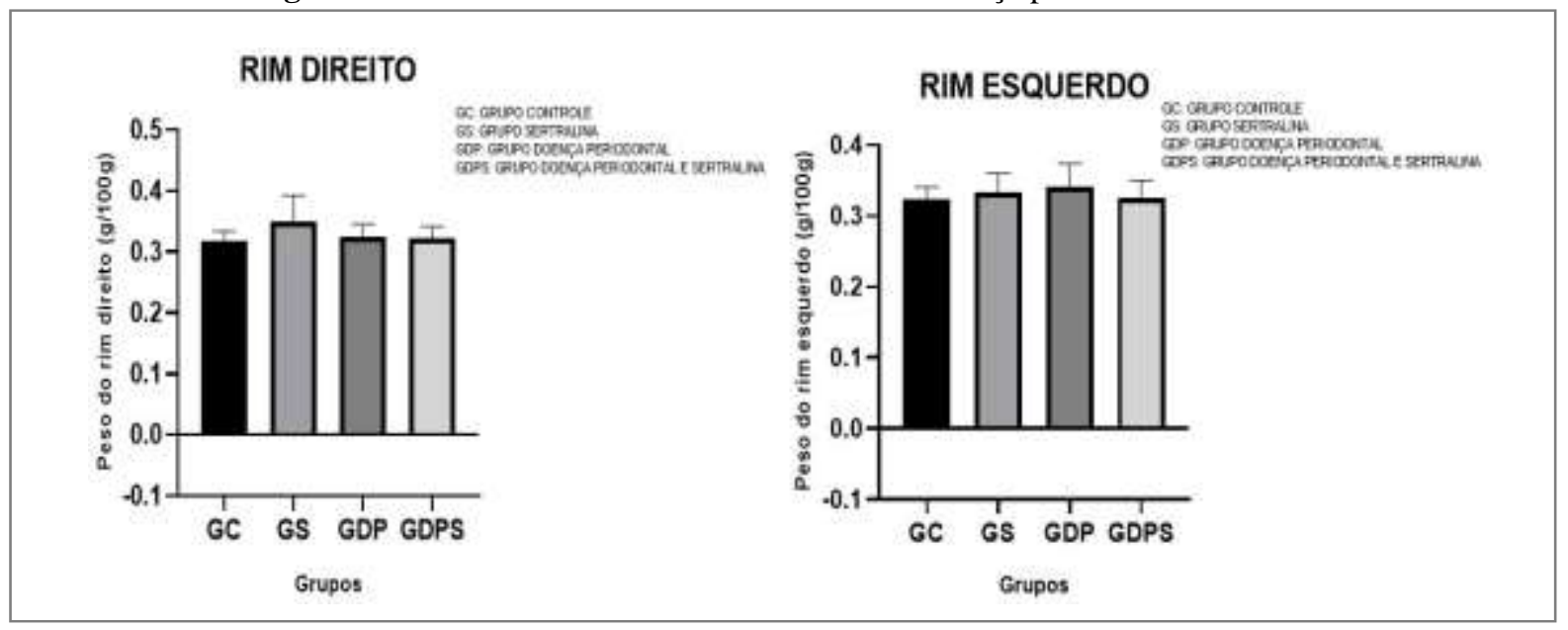

Fonte: Autores (2019). 
Gráfico 2: Gráfico da relação dos pesos dos tecidos hepáticos.

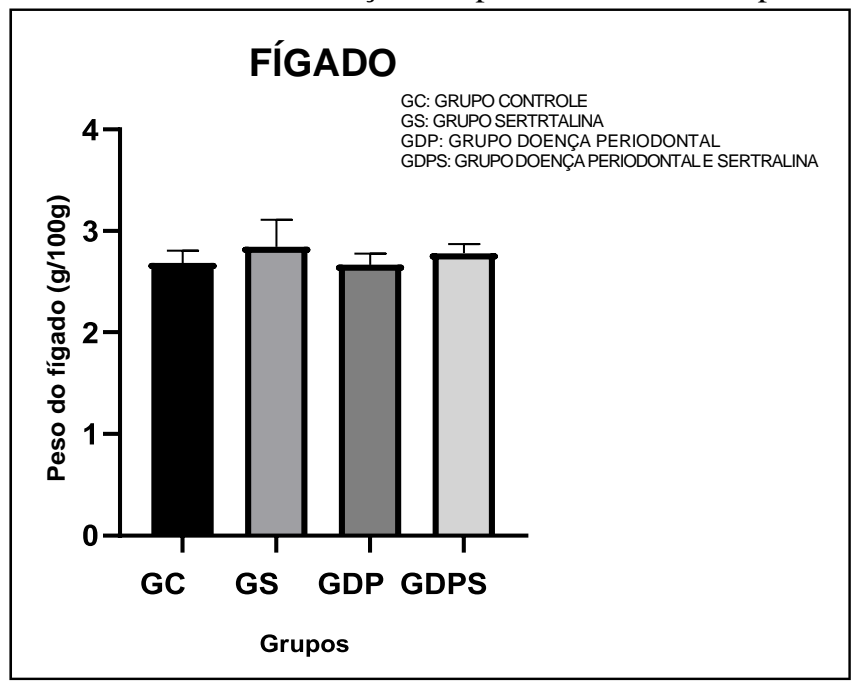

Fonte: Autores (2019).

No Gráfico 2, foi utilizado o teste de ANOVA e seguido pós teste de Tukey, avalia-se os resultados dos pesos dos fígados, os quais, também não sofreram alterações significativas em relação ao uso desta medicação $(\mathrm{p}>0,05)$.

Ao avaliar a Figura 6, com os dados estatísticos utilizados o teste de ANOVA e seguido pós teste de Tukey, notou-se que os grupos GDP e GDPS apresentam maior reabsorção óssea realizado pelo aumento de número de células de osteoclastos, isto ocorre devido a indução da doença periodontal causada pela ligadura nos $1^{\circ}$ molares inferiores. Pois, após a adição do fio de algodão número 40 nestes dentes, estes animais passaram a agregar restos alimentares nesta região, bem como, a formação do biofilme bacteriano, o qual promove a formação de abscessos, bolsas gengivais, reabsorção das fibras de colágeno, bem como, a reabsorção do osso alveolar. Assim, o uso deste procedimento mimetiza os efeitos causados por esta patologia em seres humanos, com isso, o nosso estudo corrobora com estes resultados (Foureaux et al., 2014; Alves et al., 2007).

Figura 6: Gráficos da análise da contagem de células de osteoblastos, osteoclastos e osteócitos.

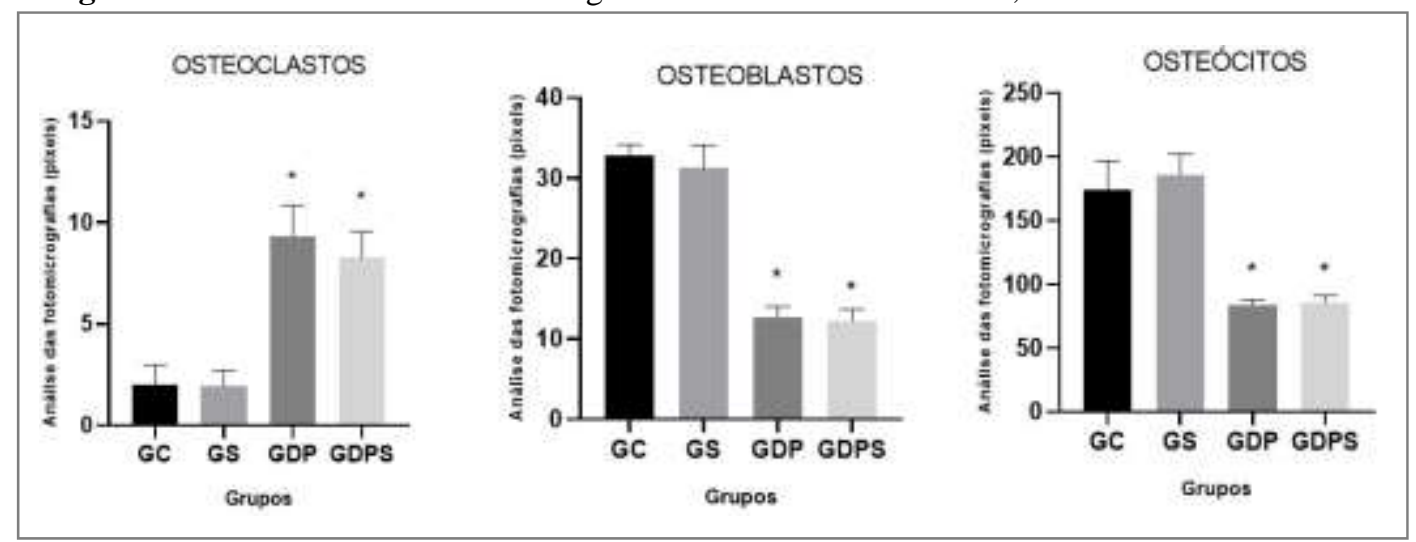

Fonte: Autores (2019).

Porém as células osteoblásticas e osteócitas se mantiveram semelhantes em relação ao GS frente ao grupo GC, isso ocorreu devido estes animais receberem apenas a medicação, suprimento alimentar e água, enquanto que nos grupos GDP e GDPS estes resultados (Figura 6) encontram-se diferentes, devido o aumento da remodelação óssea e consequentemente, a diminuição destas células (Brandão, 2015). 
No gráfico 3, referente a medida da crista óssea alveolar até a junção cemento-esmalte, foi adotado o teste de ANOVA e seguido pós teste de Tukey para a determinação os grupos GDP e GDPS que apresentaram valores estatisticamente diferentes, em relação ao grupo controle, os quais corroboram os estudos apontados por Foureaux e colaboradores (2014), ao analisarem a progressão da perda do osso alveolar em ratos com doença periodontal induzida por ligadura, entretanto o grupo GS foi semelhante em relação ao grupo controle.

Gráfico 3: Avaliação da medida da crista óssea até a junção cemento esmalte.

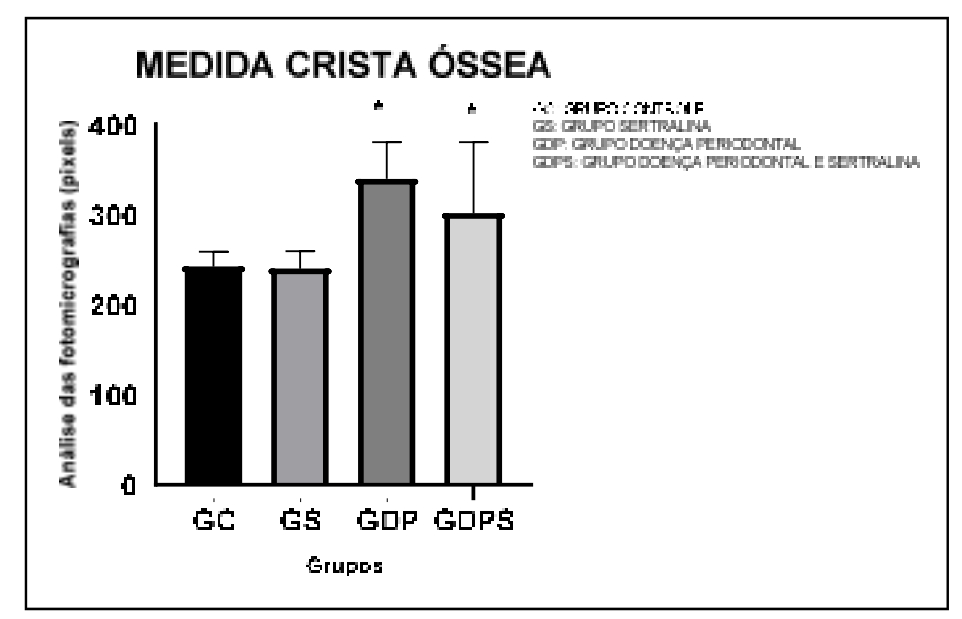

Fonte: Autores (2019).

Observou-se, na Figura 7, que o grupo controle (Figura 7-a) apresentou parâmetros dentro dos normais, tanto para o tecido epitelial e conjuntivo, bem como nenhuma perda óssea significativa, em que, o osso alveolar encontra-se compacto, regular e a junção cemento-esmalte sem alterações. Para a Figura 7-b, em que, foram administrados a medicação, suprimento alimentar e água, nota-se que o tecido epitelial e o conjuntivo encontram-se em sem sinais de alterações evidentes, bem como, o osso alveolar permaneceu intacto e a crista óssea manteve-se dentro dos parâmetros do GC. 
Figura 7: Imagem: Análise da distância da crista óssea alveolar até a junção cemento-esmalte dos primeiros molares inferiores dos animais. Fotomicrografia dos primeiros molares inferiores na coloração de Hematoxilina e Eosina, aumento de 400x através do Fotomicroscópio Olympus®. (A. Grupo Controle B. Grupo Sertralina C. Grupo Doença Periodontal D. Grupo Doença Periodontal e Sertralina

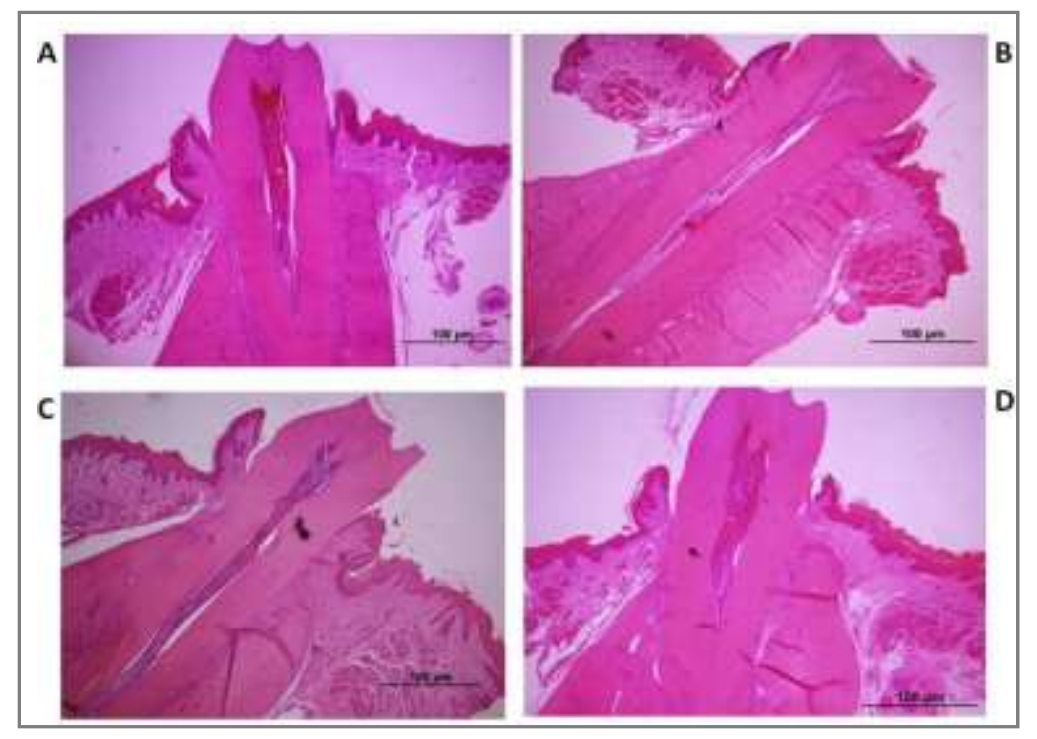

Fonte: Autores (2019).

Ao avaliarmos a Figura 7-c, o qual recebeu a ligadura nos primeiros molares inferiores, suprimento alimentar e água, nota-se a anormalidade em relação ao tecido epiteliar e conjuntivo, devido o estágio inflamatório agudo realizado pela ligadura, bem como a crista ósse em relação ao GC com presença de osteócitos e osteoblastos e presença mais exacerbada de osteoclastos.

Na Figura 7-d, em que foi submetido a ligadura, sertralina, suprimento alimentar e água, nota-se deformidades nos tecidos epiteliais, conjuntivos e na crista óssea ao ser avaliados em relação ao GC, isso ocorreu devido a presença da ligadura nestes animais, semelhante ao apresentado no Grupo Doença Periodontal.

Nas análises da morfometria dos tecidos epiteliais e conjuntivos da Figura 8, nota-se que a medicação não promoveu alteração na altura e largura dos mesmos tecidos quando comparados ao grupo controle, entretanto, os grupos GDP e GDPS promoveram diferenças estatisticamente significativas em relação ao grupo GC, através do teste de ANOVA e seguido pós teste de Tukey. 
Figura 8: Gráficos da altura e largura dos tecidos epitelial e conjuntivo.

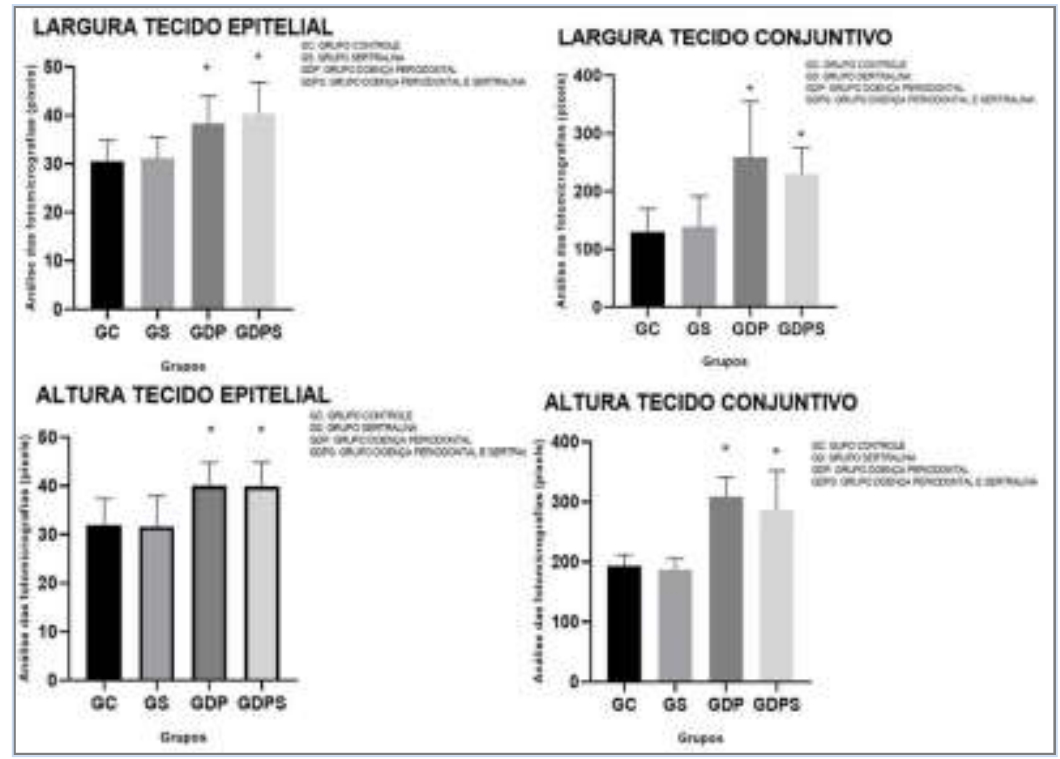

Fonte: Autores (2019).

Entretanto, ao avaliar a Figura 9 das hemi-mandíbulas do lado direito na porção mesial dos animais, notou-se que na figura 9-a. os ratos do grupo GC não apresentaram perda óssea alveolar, devido estes apenas receberem o suprimento alimentar e água, sem nenhuma intervenção cirúrgica ou medicamentosa.

Porém, ao analisar a Figura 9-b. dos animais do grupo GDP, estes apresentaram perda óssea alveolar, devido a indução da doença periodontal causada pela ligadura nos $1^{\circ}$ molares inferiores. Pois, após a adição do fio de algodão número 40 nestes dentes, estes animais passaram a agregar restos alimentares nesta região, bem como, a formação do biofilme bacteriano, o qual promove a formação de abscessos, bolsas gengivais, reabsorção das fibras de colágeno, bem como, a reabsorção do osso alveolar. Assim, o uso deste procedimento mimetiza os efeitos causados por esta patologia em seres humanos, com isso, o nosso estudo corrobora com estes resultados (Foureaux et al., 2014; Alves et al., 2007).

Figura 9. Hemi-mandíbulas esquerdas da porção mesial dos animais. A. Grupo Controle (GC); B. Grupo Doença Periodontal (GDP); C. Grupo Sertralina (GS); D. Grupo Doença Periodontal e Sertralina (GDPS).

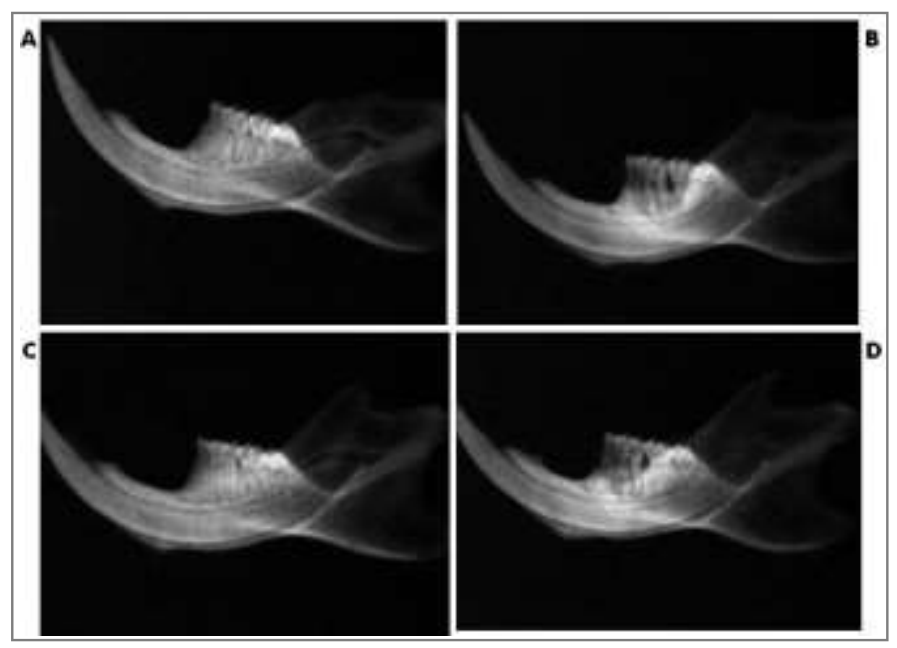

Fonte: Autores (2019). 
Na Figura 9-c, os animais do grupo GS, não apresentaram perda óssea, pois apenas ingeriram a medicação, alimentos e água, assim, este grupo apresentou semelhanças estatísticas quando comparadas ao grupo GC. No entanto, a revisão bibliográfica desenvolvida por Brandão (2015), demonstrou que o uso de medicamentos ISRS, apresentaram efeitos negativos, além de promoverem a inibição dos processos da remodelação frente a formação óssea, através do uso de implantes dentários. Assim também, animais submetidos a implantes de titânio na tíbia apresentaram efeitos negativos frente a cicatrização óssea e na osseointegração, provavelmente ao fator de diminuição do número de osteoblastos e aumento do número de osteoclastos (Abu Nada et al., 2015).

Porém, ao deparar com a Figura 9-d, notou-se que, estes animais do grupo GDPS apresentaram perda óssea alveolar, devido os mesmos possuírem ligadura nos primeiros molares inferiores, assim sendo, seus resultados são semelhantes ao grupo GDP.

Todavia, podemos avaliar estas análises estatísticas realizadas com o ANOVA - Oneway e seguido o pós-teste de Tukey, onde os valores de $\mathrm{F}$ foram 62,64 ( $\mathrm{p}=<0.0001$ ), o qual confirmou estatisticamente, que esta medicação não promoveu efeito protetor em relação a esta doença (Gráfico 4).

Gráfico 4. Avaliação da junção cemento-esmalte até a crista óssea alveolar do lado mesial.

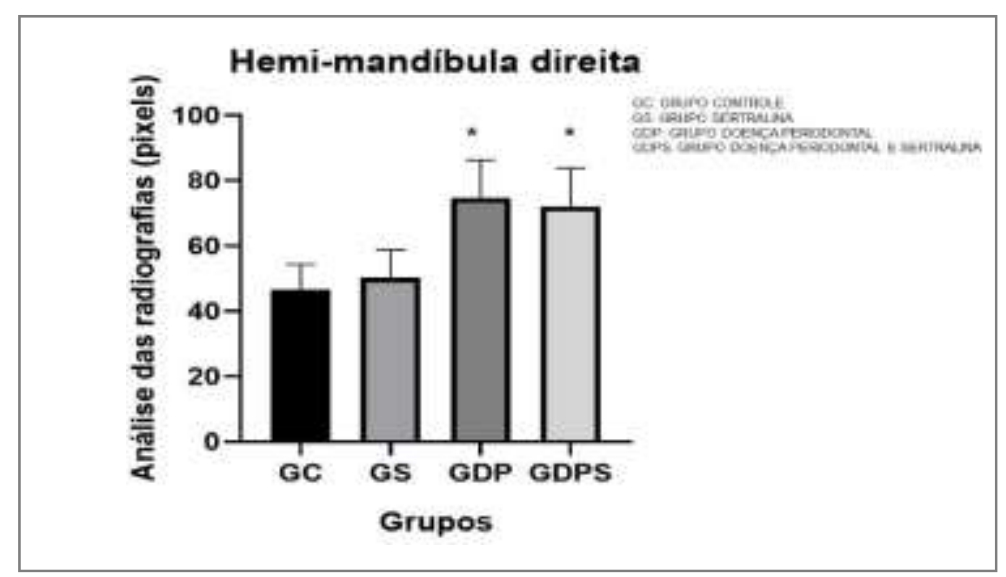

Fonte: Autores (2019).

\section{Conclusão}

O estudo aqui apresentado teve como finalidade comprovar se a sertralina, apresentava efeito protetor em relação a doença periodontal, assim como, visando a diminuição dos efeitos deletérios que podem impactar na qualidade de vida.

Os inibidores seletivos da recaptação da serotonina (ISRS) estão entre os antidepressivos mais comuns, sendo muito comum sua utilização em todo mundo. Diante dessa constatação este estudo buscou a avaliação dos efeitos da sertralina em tecidos periodontais com ratos induzidos a periodontite por ligadura.

As análises realizadas não apresentaram evidências de efeito protetor ou adverso frente a doença periodontal induzida por ligadura, portanto são necessários novos estudos clinicos laboratoriais, com um período maior de aplicação e com dosagens diferenciadas do inibidor, para concluir se esta medicação promove ou não efeito tanto positivo e ou negativo na Doença Periodontal.

\section{Referências}

Abreu, L. M. G., Lopes, F. F., Pereira, A. F. V., Pereira, A. L. A. \& Alves, C. M. C. (2010). Doença Periodontal E Condições Sistêmicas: Mecanismos De Interação. Revista de Pesquisa em Saúde, 11(2), 52-56. 
Abu Nada, L., Al Subaie, A., Mansour, A. A., Wu, X., Abdallah, M. N., Haide, A, H., Ersheidat, A., Stone, L. S., Murshed, M. \& Tamimi, F. (2018).The antidepressant drug, sertraline, hinders bone healing and osseointegration in rats' tibiae. Journal of Clinical Periodontology, 45(12), $1485-1497$.

Albuquerque, C. M. R., Pinto, A. M. G. \& Moreira, R. D. C. (2014). Doença Periodontal: Suscetibilidade genética e implicações sistemáticas. Dissertação (Mestrado Integrado em Medicina) Instituto de Ciências Biomédicas Abel Salazar/Universidade do Porto. https://core.ac.uk/download/pdf/143393405.pdf.

Atli, O., Baysal, M., Killic, GA., Killic, V., Urcarcan, S., Karaduman, B. \& Ilgin, S. (2017). Sertraline-induced reproductive toxicity in male rats: evaluation of possible underlying mechanisms. Asian Journal of Andrology, 19(6): 672-679.

Alves, C., Andion, J., Brandão, M. \& Menezes, R. (2007). Mecanismos patogênicos da doença periodontal associada ao diabetes melito. Arquivos Brasileiros de Endocrinologia \& Metabologia, 51(7), 1050-1057.

Antonini, R., Cancellier, K., Ferreira, G. K., Scaini, G. \& Streck, E. L. (2013). Fisiopatologia da doença periodontal. Revista Inova Saúde, 2 (2), $90-107$.

Assumpção, G. L. S., Oliveira, L. A. \& Souza, M. F. S. (2018). Depressão e suicídio: uma correlação. Pretextos-Revista da Graduação em Psicologia da PUC Minas, 3(5), 312-333.

Bosaipo, N. B., Borges, V. F. \& Juruena, M. F. (2017). Transtorno Bipolar: uma revisão dos aspectos conceituais e clínicos. Medicina, $50(1), 72$ - 84.

Brandão, M. M. C. (2015). Influência do uso de fármacos anti-depressivos na colocação de implantes dentários. Dissertação (Mestrado em Medicina Dentária) Faculdade de Medicina dentária/Universidade do Porto. https://repositorio-aberto.up.pt/bitstream/10216/79898/2/36149.pdf .

Brasil, Boletim Brasileiro de Avaliação de Tecnologias em Saúde. (2012). Antidepressivos no Transtorno Depressivo Maior em Adultos, 18, 1-35.

Cavagni, J., Soletti, A. C., Gaio E. J. \& Rosing, C. K. (2005). Efeito da dexametasona na patogênese da doença periodontal induzida por ligadura em ratos Wistar. Brazilian Oral Research, 19(4), 290-294.

Coltri, B. M., Costa, K. F., Pontillo, V., Bonfleur, M. L., Brancalhão, R. M. C., Beu, C. C. L., Pedrotti, S., Nassar, P. O. \& Nassar, C. A. (2017). Avaliação Morfométrica da Influência da Obesidade Sobre o Tecido Gengival de Ratos Com Periodontite Experimental. Revista Brasileira de Ciências da Saúde, 21(2), $127-132$.

Feijo, F. M., Bertoluci, M. C. \& Reis, C. (2011). Serotonina e controle hipotalâmico da fome: uma revisão. Revista Associação Medica Brasileira, 57(1),74- 77.

Foureaux, R. C., Messora, M. R., Oliveira, L. L. F., Marques, L. S., Silva, E. O., Zangerônimo, M. G. \& Pereira, L. J. (2014). Comparação de métodos para mensuração da perda óssea alveolar periodontal em ratos submetidos a estresse. Arquivos Odontologia, 50(4), 185-192.

Genco, R., Wu, T., Grossi, S., Falkner, K. L., Zambon, J. J. \& Trevisan, M. (1999), Periodontal microflora related to the risk for myocardial infarction: A case control study. Journal of Dental Research, 78(Special Issue):457.

Gil, A. C. (2009) Como elaborar projetos de pesquisa. Atlas.

Grobler, A. C., Matthews, G. \& Molenberghs, G. T. (2014). The impact of missing data on clinical trials: a re-analysis of a placebo controlled trial of Hypericum perforatum (St Johns wort) and sertraline in major depressive disorder. Psychopharmacology, 231(9), 1987-1999.

Hajishengallis, G. (2015). Periodontitis: from microbial immune subversion to systemic inflammation. Nature Reviews Immunology, 15(1), 30-44.

Jardim, S. (2011). Depressão e trabalho: ruptura de laço social. Revista Brasileira de Saúde Ocupacional, 36(123), 84-92.

Junqueira, LC. \& Carneiro, J (2008). Histologia Básica. Texto e Atlas. Guanabara.

Landau, R., Achilladelis, B., \& Scriabine, A. (1999). Pharmaceutical Innovation: Revolutionizing Human Health. Chemical Heritage Foundation.

Leishman, S. J., Seymour, G. J. \& Ford, P. J. (2013). Local and systemic inflammatory responses to experimentally induced gingivitis. Disease markers, 35(5) 543-549.

Lins, R. D. A., Pequeno, M. T., Melo, J. P. L. C., Ferreira, R. C. Q., Silveira, E. J. D. \& Dantas, E. M. (2007). Atividade ósteo-reabsortiva na doença periodontal: o papel das citocinas e prostaglandinas. Revista de Cirurgia e Traumatologia Buco-Maxilo-facial, 7, 29-36.

Mattia, T. M., Leite, M. A., Nassar, P. O., Sagae, S. C., Maller, A. C. P. A., Pandini, J. H., Cardoso, N., Marchiori, V., Brancalhão, R. M. C. \& Nassar, C. A. (2017). The influence of obesity induced by monosodium glutamate in periodontal tissues of female wister rats with experimental periodontitis. American International Journal of Contemporary Research, 7(3), 28-40.

Mootha, A., Malaiappan, S., Jayakumar, N. D., Varghese, S. S. \& Thomas, J. T. O. (2016). Efeito da periodontite na expressão da Interleucina-21: Uma revisão sistemática. International Journal Inflamation PMC - Pub Med, 1-8.

Moreno, R. A., Moreno, D. H. \& Soares, M. B. M. (1999). Psicofarmacologia de antidepressivos. Brazilian Journal of Psychiatry, $21,24-40$.

Moura, B. C. S. (2014). Monitorização terapêutica da agomelatina, sertralina e venlafaxina. Tese de Doutorado. Universidade de São Paulo. https://www.teses.usp.br/teses/disponiveis/60/60134/tde-18122014-163654/publico/Dissertacao_Completa.pdf.

Nagpal, R., Yamashiro, Y. \& Izumi, Y. (2015). The two-way association of periodontal infection with systemic disorders: an overview. Mediators of inflammation, 2015, doi: 10.1155/2015/793898.

Nassar, P. O., Nassar, C. A., Guimarães, M. R., Aquino, S. G., Andia, D. C., Muscara, M. N., Spolidorio, D. M. P, Rossa Jr, C. \& Spolidorio, L. C. (2009).

Simvastatin therapy in cyclosporine A.induced alveolar bone loss in rats. Journal of Periodontal Research, 44(4), 479-488. 
Research, Society and Development, v.10, n.6, e12210615604, 2021

(CC BY 4.0) |ISSN 2525-3409 | DOI: http://dx.doi.org/10.33448/rsd-v10i6.15604

Nery, C. S., Pinheiro, I. L., G. S., Vasconcelos, D. A. A., França, S. P. \& Nascimento, E. (2011) Medidas murinométricas e eficiência alimentar em ratos provenientes de ninhadas reduzidas na lactação e submetidos ou não ao exercício de natação. Revista Brasileira de Medicina do Esporte, 17(1), 49-55.

Newman, M. G., Michael, G., Takei, H. H., Klokkevold, P. H. \& Carranza, F. A. (2011). Periodontia Clínica. Elsevier.

Orsini, M. R. C. A. \& Ribeiro, C. R. (2012). Impacto da cronicidade do transtorno distímico na qualidade de vida. Estud. psicol., $29(1), 709-717$. https://www.scielo.br/pdf/estpsi/v29s1/07.pdf..

Pandini, J. H. (2019) Avaliação do efeito do resveratrol sobre os tecidos periodontais de ratos submetidos à periodontite experimental, Dissertação (Mestrado de Odontologia Universidade Estadual Do Oeste Do Paraná - UNIOESTE http://tede.unioeste.br/bitstream/tede/ 4502/5/Jordana_Pandini_2019.pdf.

Paula, D. M. (2007) Análise toxicológica de antidepressivos em sangue total por cromatografia em fase gasosa com detector de nitrogênio e fósforo. Dissertação (Mestrado em Toxicologia e Análises Toxicológicas). Universidade de São Paulo.

Peralta, F. S. (2008). Indução de doença periodontal em ratos previamente expostos à ciclosporina A. Dissertação (Mestrado em Odontologia). Universidade de Taubaté - São Paulo.

Prado, M. A. M. B., Francisco, P. M. S. B. \& Barros, M. B. A. (2017). Uso de medicamentos psicotrópicos em adultos e idosos residentes em Campinas, São Paulo: um estudo transversal de base populacional. Epidemiologia Servicos Saúde, 26(4), 747-758.

Rettori, E., Laurentiis, A., Zubilete, M. Z., Rettori, V. \& Elverdin, J. C. (2019). Anti-inflammatory effect of the endocannabinoid anandamide in experimental periodontitis and stress in the rat. Neuroimmunomodulation, 9 (5), 293- 303.

Rodrigues, G. F., Brisky, I. A. \& Soczek, K. L. A. (2017). Relação entre fibromialgia e depressão. (Trabalho de Conclusão de Curso da Faculdade Sant'ana). https://www.iessa.edu.br/revista/index.php/tcc/article/view/84.

Santiago, A. \& Holanda, A. F. (2013) Fenomenologia da depressão: uma análise da produção acadêmica brasileira. Revista Abordagem Gestalt, 19(1), 38-50. http://pepsic.bvsalud.org/scielo.php?script=sci_arttext\&pid=S1809-68672013000100006.

Schatzberg, A. F. \& Nemeroff, C. B. (2009). The American psychiatric publishing textbook of psychopharmacology. American Psychiatric Pub.

Schenkein H. A. \& Loos, B. G. (2013). Inflammatory Mechanisms Linking Periodontal Diseases to Cardiovascular Diseases. Journal of Clinical Periodontology, 40(14), 51-69.

Sotelo, J. L. \& Nemeroff, C. B. (2017). Depression as a systemic disease. Personalized medicine in psychiatry, 1, 11-25.

Steffens, J. P. \& Marcantonio, R. A. C. (2018). Classificação das doenças e condições periodontais e peri-implantares 2018: guia prático e pontoschave. Revista de Odontologia da UNESP, 47(4), 189-197. 